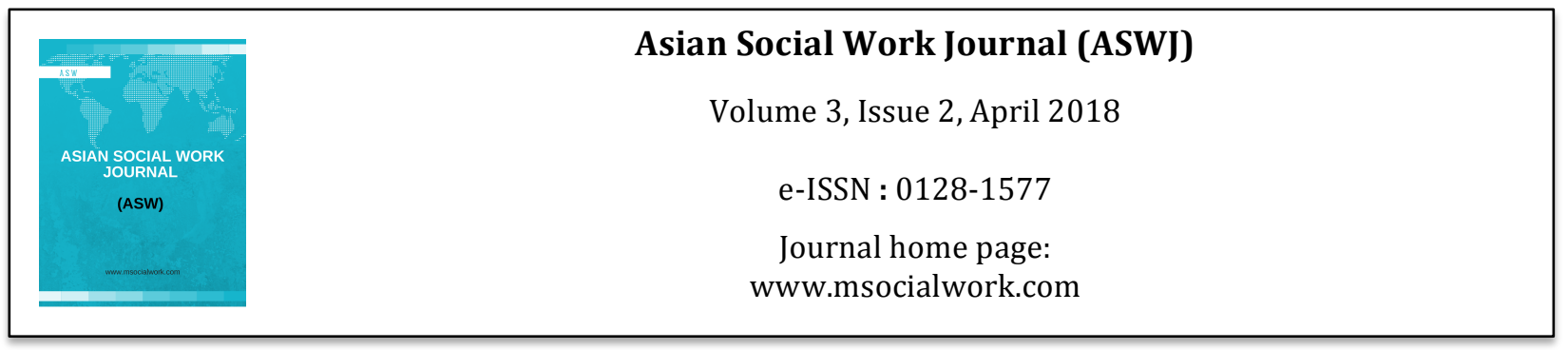

\title{
Ethical Challenges in Social Work Practice in Sri Lanka
}

\author{
K. Nanayakkara ${ }^{1}$, Bhagya Hithaishi Jayawardana ${ }^{1}$ \\ ${ }^{1}$ National Institute of Social Development, Sri Lanka
}

Corrrespondence: Bhagya Hithaishi Jayawardana (hithaishi84@gmail.com)

\begin{abstract}
Ethical practice is fundamental to any practiced based profession including social work. The social work profession is a diverse one with a mission to promote wellbeing and quality of life for vulnerable people. Despite serving the society it's also central to promoting social work Ethics to maintain the professional standards and lessen the ethical issues and dilemma's faced in day today practice. Ethics are really important to any profession, yet a necessity for those rooted in and human services. In the Sri Lankan context, it is disheartening to see how social workers have lost their professional identity with the absence of a professional code of ethics in place. A qualitative research approach was followed to explore and describe the key ethical challenges faced by the social workers in Sri Lanka. Survey method, in-depth interviews and key informants interviews were utilized and analyzed based on purposive sampling method. The data were categorized based on different themes. The finding proves that there is no proper guideline to be followed for the practitioners, particularly in situations of ethical dilemmas and conflicts. Most of the Human Service Organizations have their own set of rules with lesser focus on the code of ethical conduct. The unethical practice unintentionally promotes the malpractice leading to scenarios where organizational set of rules violates the client's self determination and confidentiality. Although most of the upcoming social work graduates are made aware of the importance of maintaining an ethical conduct, when they join the work force as social workers they face many constraints due to absence of a formal code of ethics. This has resulted most of the social workers not having any obligations to continue an ethical practice hence their practice is inevitably not much embedded in ethics. Thus the study provides an outlook on the ethical challenges faced by the social workers specially working in different sectors in Sri Lanka.
\end{abstract}

Key words: ethics, dilemma, code of ethics, social work

\section{Introduction}

Social work was formally emerged in the late 19th century. After that social workers' ideas on ethical issues have evolved since then during five periods. Social work's historical literature suggests that, for many years, the profession was focused much more on the morality of clients rather than practitioners. The phrase "professional ethics" did not exist. As social work matured, a handful of scholars and practitioners began exploring and writing rich commentaries about the profession's core values, such as client dignity, self-worth, self-determination, and confidentiality. These important discussions and analysis sought to explore the implications of social work's central values, especially when there were conflicts among the profession's values, the broader society's values, and social workers' personal values. Especially during the turbulent 1960s and early 1970s, several social work authors wrote about the complex connections between social work values and contemporary controversies surrounding civil rights, women's rights, welfare rights, discrimination, and abortion. 
The inception of social work profession was marked in 1952 officially even after 60 years it's yet being struggling to obtain it's recognition as a profession in the country. One of the foremost challenges identified was absence of code of ethics. Student social workers and professionals are facing many problems such as building rapport with agencies due to the lack of knowledge on ethics to be applied and also the clientele does not build a good rapport with social workers and the trust factor is lost and these can easily be solved by applying social work ethics and principals. This research has been carried out to find the barriers for applying ethics in the field and to find the ways of promoting knowledge.

Hence research study strive to focus on the existing challenges that have been arise due to malpractice of ethical conduct of the social work professions and it is timely to focused on the area to make a influence on strengthening the ethical practice and to form a code of ethics in order to legalize the profession within Sri Lankan context.

\section{Fundamental ethical issues and dilemmas in social work}

An ethical dilemma in its narrowest definition is "a choice between two equally unwelcome alternatives relating to human welfare" (Banks, 1995). However, ethically problematic situations are inherent in social work practice, irrespective of whether they are always acknowledged. According to Banks and Williams (2005), ethically problematic situations in social work practice can be distinguished as ethical issues, ethical problems, and ethical dilemmas. The usefulness of this distinction is to enable reflection on practitioners" thinking, stance, personal values and emotion rather than focusing on the problem itself. Based on their distinction, an ethical issue is any situation where a social worker is occupied not only with what they can do from a legal or technical perspective, but also with what they ought to do from an ethical perspective. An ethical problem is any situation where a social worker knows what they ought to do, but their moral decision is difficult to apply. Finally, an ethical dilemma is when a social worker must decide between two equally unwelcome alternatives which may involve a conflict of moral principles, and therefore the final choice will violate one of them to some degree. From this point of view, an ethical dilemma can be transformed into an ethical problem once a decision has been made, and this transformation will then reflect the social workers conscious or unconscious ethical decision-making process. A transformation of an ethical problem or issue into an ethical dilemma is also possible, and this may reflect the social workers recognition of her multiple moral obligations and the complexities of the ethical issues (Banks and Williams, 2005). The IFSW (2005) has determined four problem areas responsible for the development of ethical dilemmas in social work practice:

i. The loyalty of social workers is often in the middle of conflicting interests;

ii. Social workers function as both helpers and controllers;

iii. Conflicts between the duty of social workers to protect the interests of the people with whom they work and societal demands for efficiency and utility; and

iv. Resources in society are limited.

A range of ethical dilemmas is also raised by the tension between the ethics of autonomy, selfdetermination and paternalistic practices. These ethical dilemmas drive social workers to think of circumstances where they are obligated to intervene in the lives of others and the limits that such interventions will have. Paternalism is often thought of as the opposite of autonomy, a negation of the subject's ability to exercise their autonomy. On the other hand, autonomy derives from the acknowledgment that all people are rational beings and as such they have the right to freedom. However, autonomy relies on two conditions: the capacity of the person to reason and act rationally, and the social provision of the resources and opportunities to exercise this capacity (Bowles et al., 2006). Autonomy also means that people cannot act independently without considering the rules, both moral and statutory, of a given society. Paternalism is sometimes seen as a negative value and its positive aspects are often ignored. In fact, autonomy is often achieved through paternalism. For instance, the government may decide to intervene, exercising paternalism, in the operation of the market to ensure the equitable distribution of resources sufficient to enable people to be autonomous (Bowles et al., 2006). In reference to self-determination, the IFSW (2005) determines it as: "respecting and promoting people's rights to make their own choices and decisions, irrespective of their values and 
life choices, provided this does not threaten the rights and legitimate interests of others". This means that a person has the right to be self-determined even if they choose to engage in self-destructive behaviour, but under the condition that their choice is informed. However, self-determination and the freedom of one's choice must be restricted when another's right to well-being is at stake (Reamer, 1982).

It's been very much prominent to focus promote the right to make their own choices and decision in a process of empowering the clients than impinging the interest of social worker of other supporting officers. Those ethical guidelines have been very clearly stated in the code of ethics. The key significant of following a standard ethical guideline is it enriches the profession as well as the client service. absence of proper ethical conduct within the context has major impacts for the establishment of social work profession in Sri Lankan context.

\section{Challenges related to social work ethics in the field work practice}

\section{Less recognition for the social work profession in the country}

Even with having a recognized Social Work education program in the country Social work is still not an accepted profession in Sri Lanka. It is very appropriate to look at Social Work as a Profession in the Sri Lankan Context, and how it could contribute to the multidimensional development activities taking place in the Country today was the general consensus among the practitioners. Due to the lack of recognition in this profession in Sri Lanka, it doesn't open a platform for social work ethics to be practiced in this much needed context. The less awareness and the recognition has make absence in forming own code of ethics for social workers. Most of the social workers are not much aware about the ethical conduct. Specially the Bachelor of social work program which operates under school of social work did not had a separate study component for social work values and ethics until 2013.Most of the practitioners are less aware on area of social work ethics. The loyalty and the obligation towards the profession has been misguided due to absence of a code of ethics.

Even some field agencies are not aware on the social work ethical practice. Even the field agencies are not familiar and practice these ethical conducts. Most of the practitioners are less aware on area of social work ethics. Currently the schools of social work teach NASW and IFSW code of ethics thus it needs to be localized. In addition as there is no obligation to follow, as there is no legal or professional body to monitor the conducts of social workers. These findings portray and confirm that the Social work profession yet has no proper recognition and identification in the Sri Lankan Context hence it a challenge for social work ethics to be practiced by professionals.

\section{Less support from the field agencies}

Another 9 out of 15 participants pointed out that they had to follow agencies rules and regulations rather than applying social work ethics and skill practice because the student social workers are bound to work for the agency. Some respondents clearly stated that "It was challenging to apply ethics due to establish rules and regulations of the field agencies. The student social workers and the professionals clearly stated that they find difficulties in compelling social work ethics into some of the agency settings. Specially some organizations has no place to interview their clients. Some of the government correctional settings the inmates will be interviewed among the staff members or with other service users. As stated by one of the respondents" it's very much embarrassing to interview the client when people are around. Specially when the clients start expressing herself and start weeping over it's very challenging for the confidentiality of the service users."The field settings need to be aware on these as they are very much harmful practices for the clients.

\section{Self determination of the service users have been challenged}

Self determination is been identified as core principles and ethics under social work. It could be define as a right to take decisions and mostly the practitioners today violate the right to self determination. As 
stated by the social work practitioners mostly there has been very less space provided to promote the self determination of the clients in settings as children's home, elder's home and hospital settings. The decision for the client's problem would be mostly decided by the professionals than the service user itself. As stated by a respondent "A juvenile Delinquents, specially the victims of abuses have been institutionalized and there is no proper mechanism to distinguished the victims and offenders. Both would be institutionalized within the same system. Even a victimized child would be treated in similar manner like offenders. Within the setting they have no voice and self determination of the children have been decremented.

\section{Cultural and religious impacts}

Culture and religion has been one for the foremost challenge for many south Asian social work settings. Nonetheless due to lack of awareness and no proper ethical guidance unintentionally it's damaging the profession. As stated by remeamer it's very much unethical to continue a case morally opposing. As stated by the respondents culturally controversial issues such as commercial sex workers, abortions and LGBT are one of the most challenging field areas the social workers have value dilemma's. Most of the Islamic respondents mentioned they are not comfortable in handing cases with LGBT and Abortions as it's against the religious ethos. Even some of the Sinhala Buddhist respondents too believed it's against their culture. The social work profession has always given respect for each beliefs of the workers thus without harming the practice. The challenging fact is that most of the practitioners are not aware that continuing the cases with you are morally not agreed, create harmful effects for the service users and the best alternative is to refer the service user and to terminate the case.

\section{Conclusion}

The purpose of this study was to obtain a deeper understanding of the practice of social work ethics and the awareness about it. Focusing specifically on field work practicum, in-depth interviews were conducted with social work professionals. Importantly, this study represents the first empirical examination of social work ethics and daily practice of it. Furthermore, the qualitative orientation of the study permitted a first time opportunity for them to share in their own words, the realities of their day-to-day working lives in complex bureaucratic organizations that place little value on social work's contribution to Sri Lankan society. The study's key findings draw attention to ethical dilemmas as an inseparable part of the social work identity. Specific attention need to focus on profession's ethical commitments and the nature of the context.

\section{Recommendations}

1. In order to practice social work ethics within NISD or as a profession in Sri Lanka a Social work Code of ethics and principles relevant to Sri Lanka has to be written and constituted. It is best as the Pioneer educational institute providing social work education in Sri Lanka to make a proposal with the code of ethics and principles written on how it can be constituted to the Social Service Ministry. This will be a huge step if can be implemented as it would be much easier to follow a Social work code of ethics and principles relevant to Sri Lanka than following international code of ethics that sometime cannot be applied in certain instances.

2. It is a suggestion to make an authority to examine the violations of social work ethics not only in the field in the classrooms too. Social work ethics can be violated easily and there if no system of monitoring it. It is best suggested that violation of these ethics be monitored not only in the field settings but also in classroom because not only student's all other professionals tend violating these ethics. If and when the social work profession is given recognition and is accepted in Sri Lank, out sourced parties can be implemented to monitor these violations rather than someone within and it can have bias effects.

3. It is very important that the agency is aware about social work and its ethics. Specially the settings where the social workers have been assigned for. With proper awareness mechanism would lesson the damage and effects of unethical practices towards the service users. 


\section{References}

Banu.M, Choudhury R. H Begum. K Akter. M, Nssreen HE (2014). 'The clock keeps ticking' - the role of a community-based intervention in reducing delays in seeking emergency obstetric care in rural Bangladesh: A quasi-experimental study. Journal Public Health 128 (4), 333-340.

Bailey, C.A. (2007). A Guide to Qualitative Enquiry. USA: Sage Publications.

Banks, S. (2008). Critical Commentary: Social Work Ethics. British Journal of Social Work, 38, 12381249.

Banks, S. (2007). Between Equity and Empathy: Social Professions and the New Accountability,

Banks, S. (2005). The Ethical Practitioner in Formation: Issues of Courage, Competence and Commitment. Social Work Education, 24(7), 737-753.

Banks, S. (2003). From Oaths to Rulebooks: A Critical Examination of Codes of Ethics for the Social Professions. European Journal of Social Work, 6, 133-144.

Banks, S. (2001). Ethics and Values in Social Work. 2nd edn. London: Palgrave.

Banks, S., 1998. Professional Ethics in Social Work - What Future? British Journal of Social Work, 28(2), 213-231.

Banks, S. (1995). Ethics and Values in Social Work. London: Macmillan.

Banks, S. \& Williams, R. (2005). Accounting for Ethical Difficulties in Social Welfare Work:

Briskman, L. (2001). A Moral Crisis for Social Work: Critical Practice and Codes of Ethics.

Clark, C. (2000). Social Work Ethics. London: Palgrave.

Healy, K. (2000). Social Work Practices. Contemporary Perspectives on Change. London: Sage Publications

Reamer F.G. (1982). Ethical Dilemmas in Social Service. New York: Columbia University Press. 